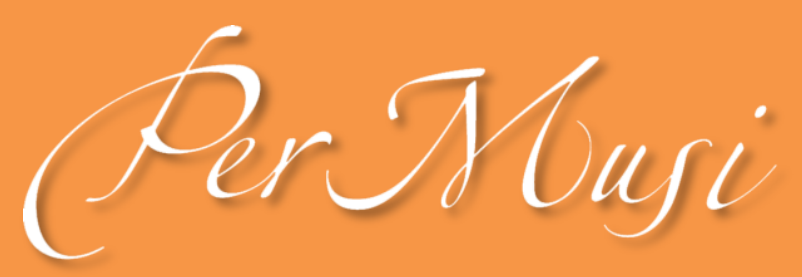

eISSN 2317-6377

\title{
Os anjinhos bem xibantes de José Maurício Nunes Garcia
}

\author{
Márcio Páscoa \\ http://orcid.org/0000-0003-0963-6577 \\ Universidade do Estado do Amazonas, Escola de Artes e Turismo \\ mpascoa@uea.edu.br \\ SCIENTIFIC ARTICLE \\ Submitted date: 09 Apr 2019 \\ Final approval date: 17 Aug 2019
}

Resumo: José Maurício Nunes Garcia escreveu dois pares de Laudate Pueri Dominum e Laudate Dominum Omnes Gentes, em 1813 e 1821 respectivamente, para serem tocados juntos nestas oportunidades. Os procedimentos compositivos demonstram que a elaboração musical obedeceu a critérios de persuasão que envolvem desde conceitos linguísticos, de natureza verbal e musical, bem como a dimensão cultural que engloba fatores socioculturais. As obras conservam dependência de compreensão entre si e compartilham aspectos infra-estruturais e estruturais, bem como as possibilidades de interpretação.

Palavras-chave: Salmos; Começo do Século XIX; Procedimentos de composição; Linguagem e música; Estruturação Musical.

\section{VERY BRAVE LITTLE ANGELS FROM JOSÉ MAURÍCIO NUNES GARCIA}

Abstract: José Maurício Nunes Garcia wrote two pairs of Laudate Pueri Dominum and Laudate Dominum Omnes Gentes, in 1813, an 1821, respectively, in order to be performed together in these occasions. Procedure of composition shows that these musical works obeys to persuasive criteria and evolves linguistic concepts, for music and words, and cultural dimension that includes social and historical issues. These psalms keep dependence of comprehension each other. Both pairs shares infra-structural and frame issues, as the likely interpretations.

Keywords: Psalms; Early $19^{\text {th }}$ century; Composition; Language and music; Musical structures. 


\section{Os anjinhos bem xibantes de José Maurício Nunes Garcia}

Márcio Páscoa, Universidade do Estado do Amazonas, mpascoa@uea.edu.br

\section{Introdução}

Passaram-se dois séculos e meio do nascimento de José Maurício Nunes Garcia e desde então as circunstâncias especiais de sua vida e o modo díspar como a posteridade o tratou e à sua obra, ainda fazem perdurar aspectos míticos da narrativa que o envolve, a compreensão estereotipada de seus afazeres como músico, e até mesmo uma distorção do entendimento sobre os demais personagens do ambiente-luso-brasileiro de seu tempo.

Preocupações mais científicas, como as de Cleofe Person de Matos, ainda que tenham resultado em um primeiro catálogo da sua obra (1970) e em uma biografia (1997), não conseguiram afastar a visão maniqueísta em que o compositor andou metido, através do discurso ideológico que dele se valeram muitos para a construção de uma necessitadíssima identidade nacional, logo a partir de meados de Oitocentos.

Foi, entretanto, muito importante que nas últimas décadas tenha se avolumado o processo de transcrição e edição de sua música, de par com estudos científicos, em teses, dissertações, livros, artigos e capítulos avulsos, que buscam iluminar ainda mais o seu ambiente cultural, rico em transformações, muitas delas decisivas para o futuro do país. Parece bem urgente que agora se busque compreender seus processos criativos ao mesmo tempo em que se revise a imagem formada por estes dois séculos de escritos sobre o autor.

Quem lida com sua obra, na condição de intérprete ou analista e ainda historiador, deve ter percebido em algum momento a forte propensão aos procedimentos de repetição de ideias musicais, de argumentos, algumas vezes apresentados na elaboração de pares de obras, ou seja, que conservam particularidades entre si e com nenhuma outra mais de seu catálogo conhecido, sejam elas assim referidas em fontes primárias ou reconhecíveis por causa das analogias que suscitam.

O caso que ora se expõe, de dois pares de salmos, envolve fontes, preferências de elaboração, metodologia e uma visão de mundo que mostra como certos assuntos eram pensados e sentidos em seu tempo. 


\section{Salmos de anjinhos bem xibantes}

Em julho de 1813, José Maurício Nunes Garcia assinava, datava e encaminhava dois salmos a um amigo seu, escondido pela alcunha de "Sr. Bidoloretes". Na dedicatória de uma das peças, o Laudate Dominum Omnes Gentes (CPM76) o compositor escreve: "Estimarei que seja a seu gosto; que seja bem ganhadeiro; he muito pequeno, de pouca gente / Viva, viva, viva, Sr. Bidoloretes / Sua Caza / aos 11 de julho / de $1813^{\prime \prime}$.

Já no rodapé da partitura do segundo salmo, Laudate Pueri Dominum (CPM77), ele escreveu (Figura 1): "Ilmo. Sr. Bidoloretes; vai o Laudate Pueri; e fica V. S. com 2 Psalmos de anjinhos bem xibantes: ambos em motivo de Rondó; e pequenos; próprios p. as vozes que quer".

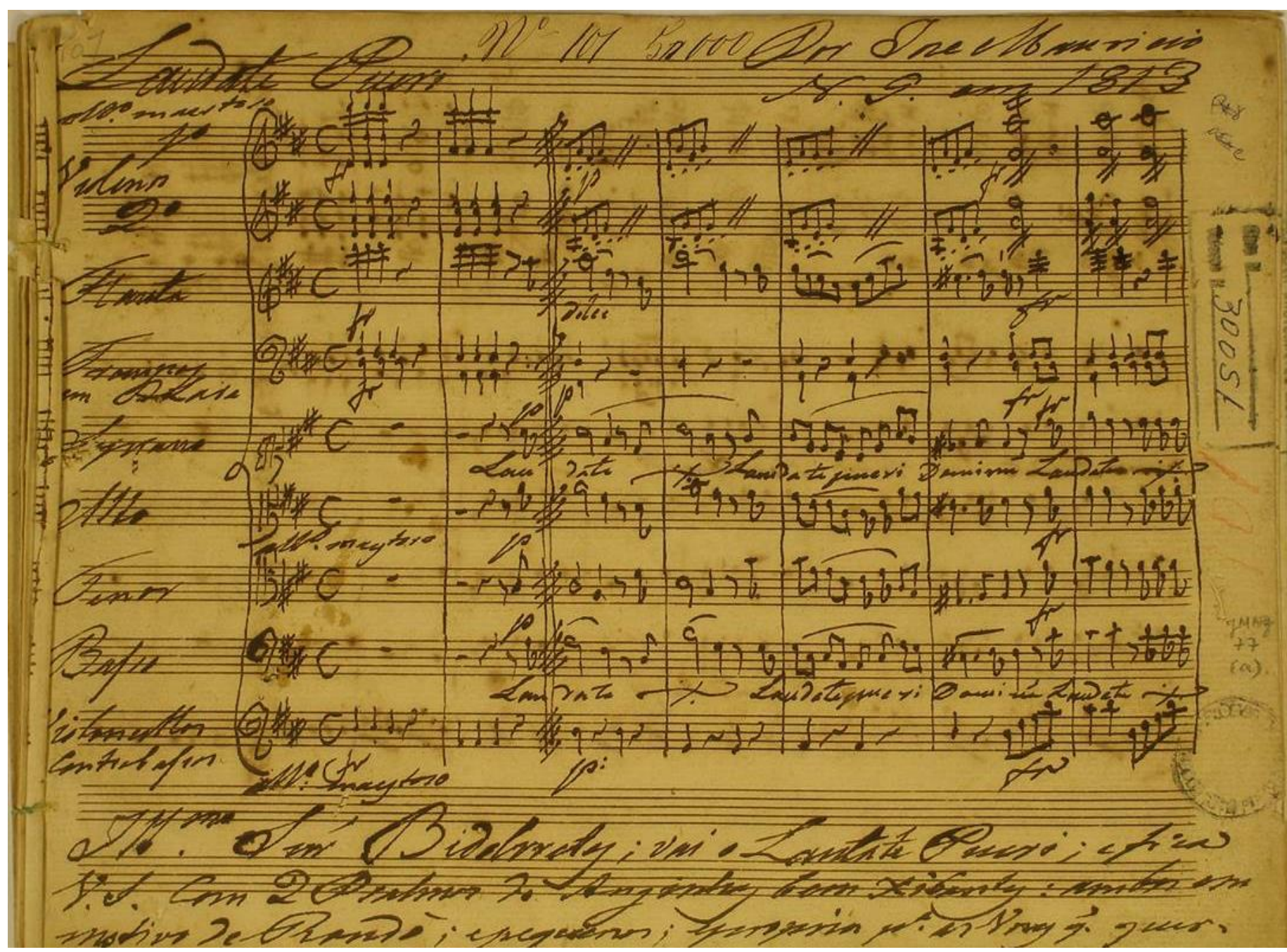

Figura 1 - Laudate Pueri Dominum (CPM77). Manuscrito autógrafo, 1813. Biblioteca Alberto Nepomuceno, Rio de Janeiro. Página de rosto com indicações paratextuais e assinatura do autor. $O$ tema do Rondó aparece com o texto Laudate após dois compassos de entrada com argumento de toque militar.

Ambas as obras são profundamente assemelhadas: estão em Ré Maior, com mesma formulação de compasso, com efetivo instrumental de flauta, 2 trompas, 2 violinos, baixo contínuo atribuído a violoncelos e contrabaixos, coro a quatro vozes, com intervenções solistas, ambas estruturadas em rondó (com andamento de Allegro maestoso), tendo ao fim a seção Sicut erat in principio...amen (com andamento de Allegro vivo), em formato imitativo. Ainda mais que isso, ambas as obras fazem o mesmo uso de vozes e instrumentos, seja por tessitura, seja por função na estruturação; a seção A do Rondó é sempre o coro com 
os primeiros versos de cada salmo; as seções alternadas B, C, etc estão sempre destinadas aos solos que carregam os restantes versos dos salmos.

Ambas as peças tem dois compassos introdutórios com claro argumento de toque militar. A tonalidade de Ré Maior de ambos os salmos coincide com a escolhida para as duas recolhas mais antigas de que se tem notícia sobre o tema, e de data próxima à elaboração das obras religiosas aqui em discussão: Toques de guerra concernentes aos clarins dos Regimentos de Cavalaria (1797) e Toques de Estado e Guerra de Clarins e Thimbales para o serviço de Cavalaria Ligeira dos Mandamentos Regulares (antes de 1797). Este manual possui 36 toques, sendo 19 deles para serviços e continência e os restantes para Guerra. No outro manual, de 1797 há um número maior de toques e usos, incluindo um muito sugestivo, chamado Toque das Ave Marias, que tinha seu uso sempre após o Toque das retretas (usado para o recolhimento, apagar das luzes e dormir) e o Toque da Diana (usado para o despertar das tropas, e dar ordem de levantar ao amanhecer), associação provável com as horas canônicas, não só pela eficácia do canto na sua relação com o regramento do coletivo (mosteiro - caserna) mas porque se cantava sempre nestas horas um hino mariano, independente da restante quantidade de texto e música que podia variar.

A tonalidade de Ré Maior destes manuais de toques militares é relativa ao uso do instrumento que se usava (Sousa 2012, 4). Deve-se apenas alertar para o fato de que a variedade de toques admitidos pelo exército português ao tempo da obra de José Maurício Nunes Garcia cresceria ainda mais, com a adoção em 1810 da regulamentação inglesa, de William Beresford (1806), que ampliou repertório, usos, preceitos e contribuiu para assemelha-los com os toques dos demais exércitos aliados na campanha antinapoleônica, como os da Prússia, Itália e Inglaterra (Sousa 2012, 3). Assim, toques com figuração rítmica de menor valor passaram a indicar velocidade de marcha, enquanto os toques menores ou de valores mais longos se destinaram a outras atividades como, por exemplo, prestar continência.

Os dois compassos introdutórios dos citados salmos de Garcia têm, portanto, uma função exordial significativa na estruturação deste discurso composto pelo músico carioca. Eles não só realizam a captatio benevolente, a chamada de atenção (a prestação de continência), como dão o tom do despertar para a palavra do louvor (Laudate). Muitas obras deste compositor possuem este tipo de entrada e sobretudo aquelas que foram sensivelmente compostas em pares, para provável uso associado como o Te Christe Solum Novimus (CPM 52), cuja carátula traz a indicação de 1800, e o Creator Alme Siderum (CPM 59), esta conservada em cópia pertencente à Lira Sanjoanense, enquanto a primeira integra o acervo da Biblioteca Alberto Nepomuceno, do Rio de Janeiro (EM4243v.3099). Curiosamente neste caso, o carioca usou dois textos oriundos da mesma fonte, um argumento extraído do Hino das Laudes de louvor a Cristo, tradicional do Breviário Romano e usado na quarta-feira da primeira e terceira semana do Saltério durante o Tempo Ordinário e que foi corrigida pelo papa Urbano VIII na versão que publicou do citado breviário em 1632. Ambas as peças foram estruturadas em dois movimentos, o primeiro só com a primeira quadra das respectivas versões do Hino (Si bemol Maior para o Te Christe, Fá Maior para o Creator...) e o segundo movimento um Decantabo... Aleluia em forma de Rondó em Fá Maior para as duas peças, sempre estruturadas para solo de soprano, flauta(s) trompas e cordas a quatro. 


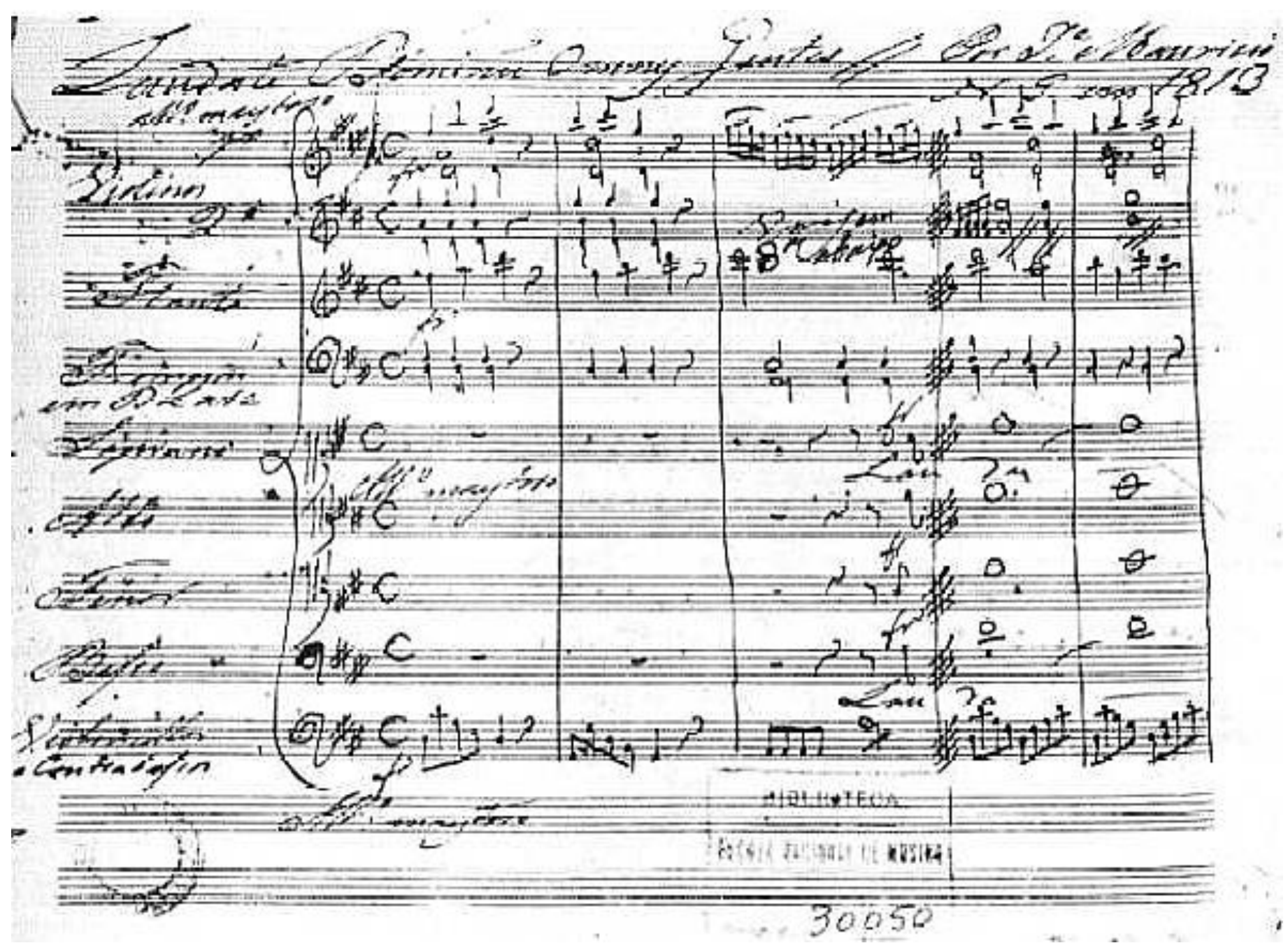

Figura 2 - Laudate Dominum Omnes Gentes (CPM 76) Página de rosto. Manuscrito autógrafo. Fonte: Biblioteca Alberto Nepomuceno. Dois compassos de toque militar (c. 1-2) e primeiros compassos do tema A do coro, com a invocação de louvor: Laudate (c. 4-5)

O salmo Laudate Dominum Omnes Gentes (Salmo 116) tem elaboração textual breve e gerou seções B (solo de Soprano), C (solo de Baixo) e D (dueto solista de Alto e Tenor), antes do coro final; a seção D já inicia, entretanto, a doxologia, o Gloria Patri, enquanto a estrutura imitativa final se ocupa de sua segunda parte, o Sicut erat in principio.

Tabela 1 - Distribuição textual e musical pela estrutura do Laudate Dominum Omnes Gentes (CPM 76)

\begin{tabular}{lll}
\hline Laudate Dominum Omnes Gentes, omnes populi & c.3-29 & \multicolumn{1}{c}{ Coro } \\
\hline $\begin{array}{l}\text { Quoniam confirmata est, super nos misericórdia ejus. } \\
\text { Et veritas dominum manet in aeternam }\end{array}$ & c.30-54 & $\begin{array}{l}\text { Solo } \\
\text { Soprano }\end{array}$ \\
\hline $\begin{array}{l}\text { Laudate Dominum Omnes Gentes, omnes populi } \\
\text { Quoniam confirmata est, super nos misericórdia ejus. } \\
\text { Et veritas dominum manet in aeternam }\end{array}$ & c.59-86 & Coro \\
\hline $\begin{array}{l}\text { Laudate Dominum Omnes Gentes, omnes populi } \\
\text { Gloria Patri, gloria Filio et spiritui sancto }\end{array}$ & $\begin{array}{l}\text { Solo } \\
\text { Baixo }\end{array}$ \\
\hline $\begin{array}{l}\text { Laudate Dominum Omnes Gentes, omnes populi } \\
\text { Sicut erat in principio, et nunc, et semper, et in saecula } \\
\text { saeculorum. Amen }\end{array}$ & c.184-146-164 & Dueto Alto e Tenor Seção C \\
\hline
\end{tabular}

O Laudate Pueri Dominum (Salmo 113) por sua vez tem texto maior e o compositor elaborou, para além da seção A (coro com versos de incipit), seções B (solo de Soprano), C (solo de tenor), D (solo de Baixo), E (solo 
de Alto) e F (solo de Soprano, outra vez); em todas estas seções, exceto $D$, o solista se vê acompanhado das restantes vozes em coro no estilo declamativo sobre texto do primeiro verso, à guisa de comentário.

A última seção solista, neste caso o dueto, ficou como no outro salmo, encarregada da primeira parte da doxologia e o coro ao final, com a segunda parte.

Tabela 2 - Distribuição textual e musical pela estrutura do Laudate Pueri Dominum (CPM 77)

\begin{tabular}{llll} 
Laudate Pueri Dominum, laudate nomen domini & c.2 - 17 & Coro & Seção A \\
\hline Sit nomen Domini benedictum ex hoc nunc et usque in & c.18 - 41 & Solo Soprano (e Coro) & Seção B
\end{tabular}
saeculum.

A solis ortu usque ad occasum laudabile nomen Domini

$\begin{array}{llll}\text { Laudate Pueri Dominum, laudate nomen domini } & \text { c.43 - 55 } & \text { Coro } & \text { Seção A } \\ \begin{array}{lll}\text { Excelsus super omnes gentes Dominus, et super caelos gloria } \\ \text { ejus }\end{array} & \text { c.57-83 } & \begin{array}{l}\text { Solo } \\ \text { Tenor (e coro) }\end{array} & \text { Seção C }\end{array}$

Quis sicut Dominus Deus noster, qui in altis habitat,

et humilia respicit in caelo et in terra?

\begin{tabular}{|c|c|c|c|}
\hline Laudate Pueri Dominum, laudate nomen domini & c. $85-97$ & Coro & Seção A \\
\hline $\begin{array}{l}\text { Suscitans a terra inopem, et de stercore erigens paupere } \\
\text { ut collocet eum cum principibus, cum principibus populi sui. }\end{array}$ & c.99-124 & $\begin{array}{l}\text { Solo } \\
\text { Baixo }\end{array}$ & Seção D \\
\hline Laudate Pueri Dominum, laudate nomen domini & c. $126-138$ & Coro & Seção A \\
\hline $\begin{array}{l}\text { Qui habitare facit sterilem in domo, matrem filiorum } \\
\text { laetantem }\end{array}$ & c. $142-178$ & $\begin{array}{l}\text { Solo } \\
\text { Alto } \\
\text { (e coro) }\end{array}$ & Seção E \\
\hline Laudate Pueri Dominum, laudate nomen domini & c.181-193 & Coro & Seção A \\
\hline Gloria Patri, gloria Filio et Spiritui Sancto & c. $195-210$ & Solo Soprano (e Coro) & Seção F \\
\hline Laudate Pueri Dominum, laudate nomen domini & c. $214-226$ & Coro & Seção A \\
\hline $\begin{array}{l}\text { Sicut erat in principio, et nunc, et sempre, in saecula } \\
\text { saeculorum. Amen }\end{array}$ & c. $228-288$ & Coro & Coda \\
\hline
\end{tabular}

Como no outro salmo, existem interlúdios instrumentais entre as seções, por onde o compositor deu destaque à flauta, que também acompanham os solistas em todas as suas intervenções (Figura 3). 


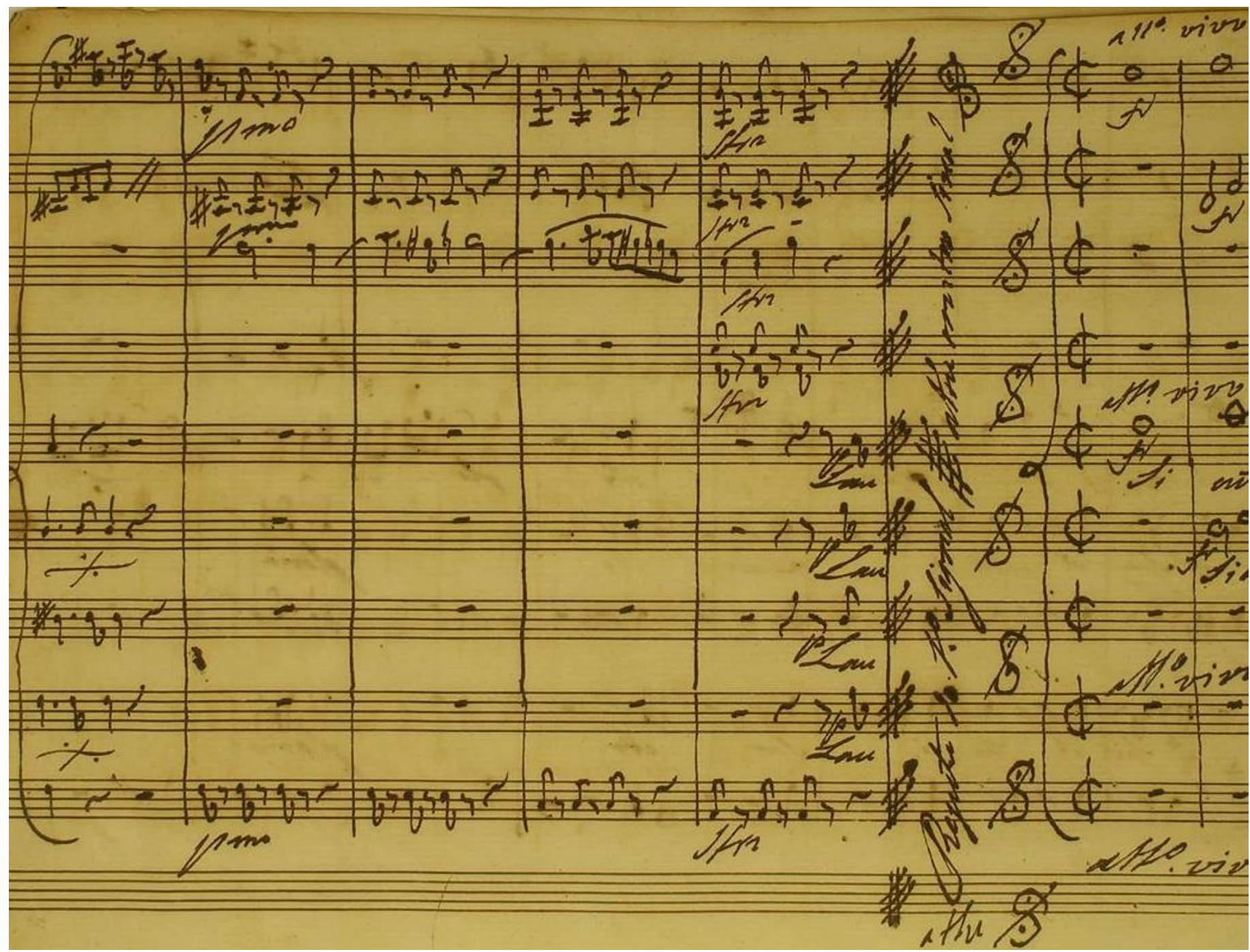

Figura 3 - Laudate Pueri Dominum (CPM77). Manuscrito autógrafo, 1813. Biblioteca Alberto Nepomuceno, Rio de Janeiro. Nesta página vêse o fim da Seção F, indicação de retomada da seção A e entrada da segunda parte da doxologia, Sicut erat in principio (Allegro vivo)

A divisão textual, assim como no Laudate Dominum Omnes Gentes, tentou obedecer a uma regular organização dos versos e a uma espécie de variação de topos interna do texto: geralmente a exegese encontrada destes textos tende a organiza-los a cada dois ou três, e é possível que esta seja uma prática histórica, haja visto que José Maurício Nunes Garcia mudou condições de escrita, sobretudo harmonia, figuração e flutuação tonal, mas também uso de esquemas de contraponto particulares, em cada uma das seções de interpolação. A única seção que excede tal formalidade é a que foi atribuída o solo de tenor (C) que canta 8 versos (versos 4 a 11) dos 18 disponíveis.

A atenção ao texto era uma das premissas do tempo (Suzler 1792, 271-274 apud Baker; Christensen 1995, 54), o que não significa que as emoções suscitadas inicialmente precisassem ser extáticas. Ao contrário, deve-se considerar para além da exegese textual, quais sentimentos o compositor pretendeu despertar e com isso qual o planejamento estético que ele entendeu para a obra e todas as alterações que ele provocou, de modo a conduzir as emoções do ouvinte, e como manipulou as variáveis, que aqui são encontradas (Idem).

Isso porque todos os solos de ambos Laudate não estão em condições estáveis perante o disposto na seção A e em alguns casos a tendência à flutuação harmônica é a evidente rejeição à ideia de afeto único não só para a seção, mas para a obra inteira. A estratégia se aproxima da noção de manipulação de sentimentos subsequentes, às vezes simultâneos, como forma de construir argumentação mais convincente sobre o 
caráter da obra (Idem). Não só a progressão harmônica, independente de metrificação musical, é evidência disto, conforme notava Sulzer na produção musical a partir da segunda metade do século XVIII, mas a variabilidade de melodia e ritmo, a mudança do metro, a mudança dinâmica das notas e de frases, a própria escolha do acompanhamento (instrumentação e distribuição de forças vocais), bem como a digressão tonal para campos mais distantes (Idem).

No Laudate Dominum Omnes Gentes, por exemplo, o compositor distribuiu os seguintes versos do salmo para o solo de soprano e o solo de baixo, fazendo com que os dois oradores/cantores de cada voz repetissem integralmente este texto:

\section{Quoniam confirmata est / super nos misericórdia eius / et veritas domini / manet in aeternum \\ Pois está confirmada / sobre nós a sua misericórdia / \\ E a verdade do Senhor / Permanece para eternidade.}

As elaborações para estas seções B e C, são afirmativas tanto pelo uso constante do modo maior nas melodias de soprano e baixo, associadas com a repetição do trecho confirmata est (acentuando o sentido decisivo, definitivo) e as cadências ascendentes do último par de versos (em que a verdade do Senhor é declarada eterna como num crescendo esplendoroso), de modo a direcionar descendentemente em ambos os solos a melodia dos dois primeiros versos em que o sentido principal é a misericórdia divina que se impõe sobre os Homens. As diferentes elaborações de figuração e maneira de conduzir a progressão harmônica fazem parte, portanto como teorizava Sulzer duas décadas antes, do que o autor germânico entendia como as abordagens particulares de interpretar o texto por parte de quem inventa a música (o termo é de Sulzer, certamente em algum nível de conexão com a Retórica), norteando consequentemente os executantes a aspectos particulares que são precisamente as diferenças expressivas que cada um deve buscar e às quais deve potencializar a partir do texto verbal e musical.

A diferença de elaborações harmônicas para estes versos, em relação ao estabelecido nos versos do incipit, já seriam suficientes para Forkel $(1788,13)$ asseverar que a expressão mudou, porque mudaram os sentimentos acerca do argumento musical, e se alguns elementos ainda permanecem, é porque aspectos da sua expressão ainda se relacionam a ideia principal, mas podem estar justapostos, superpostos (Idem), variados da norma estabelecida pelo autor, quando escolheu seus assuntos (temas musicais).

A melhor explicação para a noção de uso de norma e variação é a adoção da estrutura de Rondó, que deixa clara nos vários retornos à seção $A$, a premissa maior de ambos os salmos pela repetição de seus incipit:

\section{Laudate Dominum Omnes Gentes / laudate eum omnes populi \\ Louvem o Senhor todas as nações, louvem-no todas as pessoas \\ Laudate pueri Dominum / laudate nomen domini \\ Louvai o senhor, crianças, louvai o nome do senhor.}

Isso pode ser ratificado também em termos de planejamento retórico, inclusive, pois ambos salmos contam com o retorno ao primeiro verso como confirmatio, uma vez que eles são argumentos da narratio. A disposição dos passos discursivo-musicais pelo compositor brasileiro não é linear em nenhum dos casos; neste sentido, deve-se lembrar sempre que o planejamento discursivo é infra-estrutural. No Laudate Dominum Omnes Gentes nem mesmo há uma refutação à assertiva inicial, e os trechos de flutuação a tonalidade menor está mais próximo de um sentido tópico transitório. Todos os versos seguintes ao inicial 
são na verdade exegéticos e a reafirmação da seção A ganha contornos cada vez mais assertivos, porque confirmam e até mesmo abrem os apelos finais (peroratio).

Foi por causa da associação de sinais musicais que expressam sentimentos humanos, o que remonta a Descartes, mas, sobretudo, evoca Rousseau por causa da sua variabilidade dinâmica em pleno curso, que alguns teóricos aludiram a aspectos semióticos da interpretação de tais contextos (Hatten 1994; 2006; 2014; Monelle 2006), pois, afinal, a origem dos ideais setecentistas evocava uma espécie de doutrina da mímesis, e assim a música comunicava expressões humanas conforme não só a natureza dos próprios seres humanos, mas impulsionada pelo conceito (aliás, vasto) de Natureza; para uns como Chabanon, a rejeitar tal doutrina, o ser humano é mero instrumento, e outros em sentido contrário, como Rousseau, o Homem é amplamente dotado de faculdades que "interpretam" o mundo sensorialmente e espiritualmente e por ele se influenciam diversamente. Esta equação de sinais imitativos da Natureza (ícones) que o compositor produziu como expressão (índice), contendo também sinais de emoção (índices) e, portanto, pertencentes à relação com o Natural (Mirka 2014, 28) foi desenvolvida em diversas análises, embora alguns autores com o mesmo ferramental, como Monelle e Mirka, tenham produzido resultados diferentes, levando imediatamente a ressalvar que a ideia de trabalhar os tópicos deve ser suficientemente flexível por um lado e muito consciente do modelo teórico por outro, para que se evitem fragilidades teóricas e uma mera repetição pouco desenvolvida, mal conceituada e consequentemente equivocada do assunto (Caño 2018).

Entretanto é aliciante a ideia de Hatten sobre o que ele conceitua como tropificação, fazendo uso assim de uma associação semiótico-retórica, ou seja, quando um signo expressivo - a figuração musical, é usado para modificar ou transformar o efeito de um segundo (Hatten 1994). Usando o conceito de maneira mais desenvolvida poder-se-ia dizer que os tópicos usados aqui por José Maurício Nunes Garcia, mesmo que flexivelmente delimitáveis (e eles podem ser entendidos como sendo marcha, hino processional, ou outros modelos), mas demonstráveis pelas interpolações das seções e os frequentes retornos ao A, fariam parte de uma estratégia de tropificação; necessário entender aqui que a superposição textual em que cada narrativa tem seu caráter (num sentido de Sulzer, ou seja, como sentimento ou afeto não extático), provoca as citadas alterações de sentido, também considerada pela categorização que Hatten faz quando conceitua tempo e temporalidade (Hatten 2006 apud Almen; Pearson 2006, 62-75), pois as narrativas independentes da manipulação dos parâmetros métricos da música (tempo), podem conservar motivos musicais a um ponto em que a discurso musical em seu curso retém ideias e, portanto, significados e com isso a noção temporal interna da peça.

Laudate Pueri Dominum só ou em associação com o outro salmo, enriquece ainda mais a discussão. 0 significado global do primeiro verso faz paralelo com o outro Laudate (que se refere a um coletivo de nações, de povos). Embora puer signifique menino, Virgílio o usou metonimicamente como um coletivo infantil, daí ser costumeiramente traduzido como criança, e assim foi largamente empregado o vocábulo. Desse modo, a associação dos dois salmos provoca a referência à Humanidade dividida em duas categorias, mas pertencentes a um mesmo coletivo humano, o que pode ser entendido em música pela compartilha de diversos valores comuns, incluindo os argumentos musicais e os parâmetros já teorizados por Sulzer: assim a música é muito semelhante em ambos porque assuntos e seus contornos são também assemelhados. Restaria então entender, para além da norma e suas variantes, os pontos de eventual discordância, necessários como estratégia discursiva. 
Apenas no solo de contralto (Qui habitare, figura 4), a tonalidade muda para uma opção em tom menor, perfeitamente reconhecível como a Confutatio do planejamento discursivo restante, que é todo em tonalidades maiores, especialmente o final brilhante e apoteótico.

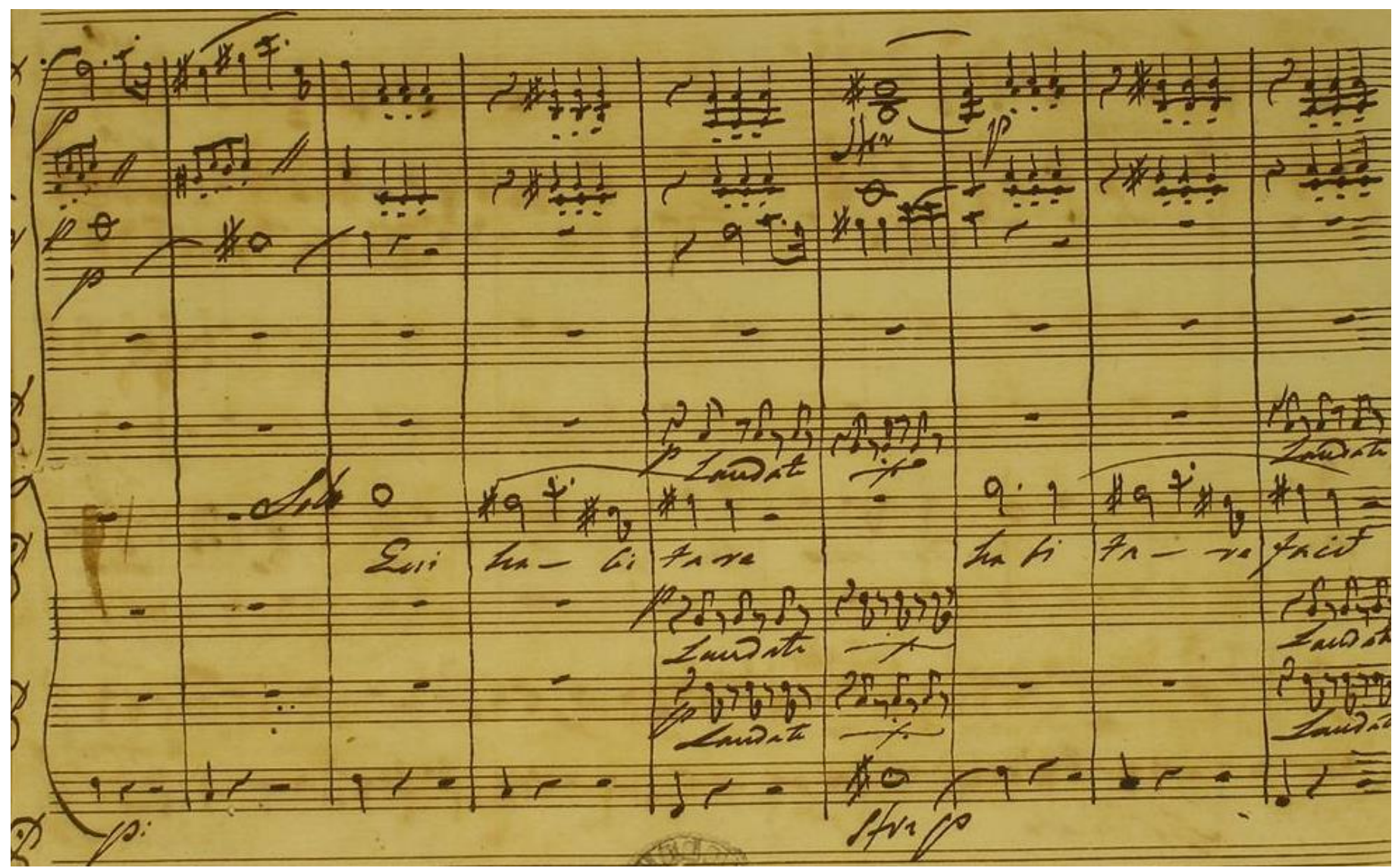

Figura 4 - Laudate Pueri Dominum. Qui habitare (Solo de contralto). Manuscrito autógrafo, p. 4. Fonte Biblioteca Alberto Nepomuceno

Entretanto, aportes histórico-sociais são inevitáveis para a compreensão destas obras. Os anjinhos a que se refere Garcia em seus salmos de 1813 eram entendidos àquele tempo por inocentes defuntos, as crianças da comunidade que haviam falecido e de quem se fazia encomendação das almas. A associação do termo bem xibantes (ou chibantes), pode significar ainda algo mais. Por xibante se designava à época alguém que se faz de forte, atributo de quem é guapo, bravo, valente, picão; e por guapo tomava-se alguém animoso, arriscado, atilado, loução e galante (Silva 1789, 388). Seriam os anjinhos, bravos inocentes em curso ao paraíso ou seriam os dois salmos, peças aprimoradas que, embora pequenas, revelassem o caráter valente da música e o seu argumento interpretativo? Ambas as coisas parecem indissociavelmente associadas neste contexto.

O relato subsistente do teólogo e poeta espanhol José Blanco White (1775-1841), nascido e criado em Sevilha, em carta datada de 1806 (Letter IX), expõe de maneira inequívoca os costumes católicos que servem aos salmos de anjinhos xibantes de Garcia:

From the birth to the death of a child the passage is often so easy that I shall make it an apology for the abruptness of the present transition. The moral accountableness of a human being, as I have observed before, does not, according to Catholic divines, begin till the seventh year; consequently such as die without attaining that age, are, by the effect of their baptism, indubitably entitled to a place in heaven. The death of an infant is therefore a matter of rejoicing to all but those in whose bosoms nature speaks too loud 
to be controlled by argument. The friends who call upon the parents, contribute to aggravate their bitterness by "wishing them joy" for having increased the number of angels. The usual address on these occasions is Angelitos al Cielo! Little Angels to Heaven - an unfeeling compliment, which never fails to draw a fresh gush of tears from the eyes of a mother. Every circumstance of the funeral is meant to force joy upon the mourners. The child, dressed in white garments, and crowned with a wreath of flowers, is followed by the officiating priest in silk robes of the same colour; and the clergymen who attend him to the house from whence the funeral proceeds to the church, sing in joyful strains the psalm Laudate, pueri, Dominum [grifo meu], while the bells are heard ringing a lively peal. The coffin, without a lid, exposes to the view the little corpse covered with flowers, as four well-dressed children bear it, amidst the lighted tapers of the clergy. No black dress, no signs of mourning whatever are seen even among the nearest relatives; the service at church bespeaks triumph, and the organ mixes its enlivening sounds with the hymns, which thank death for snatching a tender soul, when through a slight and transient tribute of pain, it could obtain an exemption from the power of sorrow. Yet no funerals are graced with more tears; nor can dirges and penitential mournings produce even a shadow of the tender melancholy which seizes the mind at the view of the formal and affected joy with which a Catholic infant is laid in his grave (White 1822, 154-155) ${ }^{1}$.

Garcia compôs oito anos depois um outro par de Laudate Dominum Omnes Gentes (CPM78) e Laudate Pueri Dominum (CPM79), com as mesmas intenções e com recomendações paratextuais ainda mais explícitas. Foram ambos salmos destinados às exéquias de infantes inocentes e possuíam um fundamento temático que os unia. Preservados em cópia autógrafa e arrumados num mesmo volume oblongo, trazem na carátula de cada partitura os mesmos dizeres (Figura 5):

${ }^{1}$ Desde o nascimento até a morte de uma criança, a passagem é tão simples que vou pedir desculpas pela brusquidão da presente transição. A responsabilidade moral de um ser humano, como observei antes, não começa, segundo os católicos, até o sétimo ano; conseqüentemente, morrer desta maneira sem atingir essa idade, dá, por efeito do batismo de tais infantes, o direito indubitável a um lugar no céu. A morte de uma criança é, portanto, uma questão de regozijo para todos, exceto aqueles em cujo peito a natureza fala muito alto para ser controlada pelo argumento. Os amigos que recorrem aos pais, contribuem para agravar sua amargura, ao "Ihes desejar alegria" por terem aumentado o número de anjos. A fala habitual nessas ocasiões é Angelitos al cielo, Pequenos Anjos ao Céu - um cumprimento insensível, que nunca falha em extrair uma torrente de lágrimas dos olhos de uma mãe. Toda a circunstância do funeral tem o objetivo de forçar a alegria dos enlutados. A criança, vestida de roupas brancas e coroada com uma guirlanda de flores, é seguida pelo sacerdote oficiante em vestes de seda da mesma cor; e os clérigos que o acompanham à casa de onde decorre o funeral dirigem-se à igreja, cantam em tensa alegria o salmo Laudate, pueri, Dominum [grifo meu], enquanto os sinos se ouvem em vibrante repique. O caixão, sem tampa, expõe à vista o pequeno cadáver coberto de flores, assim como as quatro crianças bem-vestidas que o sustentam, em meio às velas acesas dos clérigos. Sem vestes pretas, nem sinais de luto no que se vê, nem mesmo entre os parentes mais próximos; o serviço na igreja remete ao triunfo, e o órgão mistura seus sons animados com os hinos, que agradecem a morte por roubar uma alma terna, quando através de um leve e transitório tributo de dor, poderia obter uma isenção de poder à tristeza. No entanto, nenhum funeral é agraciado com mais lágrimas; nem os cantos fúnebres e os lamentos penitenciais produzem sequer uma sombra da terna melancolia que vem à mente diante da alegria formal e afetada com a qual uma criança católica é colocada em seu túmulo [Tradução do autor]. 
Psalmo / Para as encomendaçoens dos Innocentes falecidos / com Duas Rabecas, duas Clarinetas, duas [2] Trompas, 4 vozes e Baixo / Composto no anno de 1821 / pelo Pe. José Maurício Nunes Garcia, e / arranjado sobre alguns motivos da grande obra / da Creação do Mundo do Imortal Haydn / e offerecido / ao Sr. João dos Reis Pereira por seu autor (Registro 398/2007. Sistema 349026).

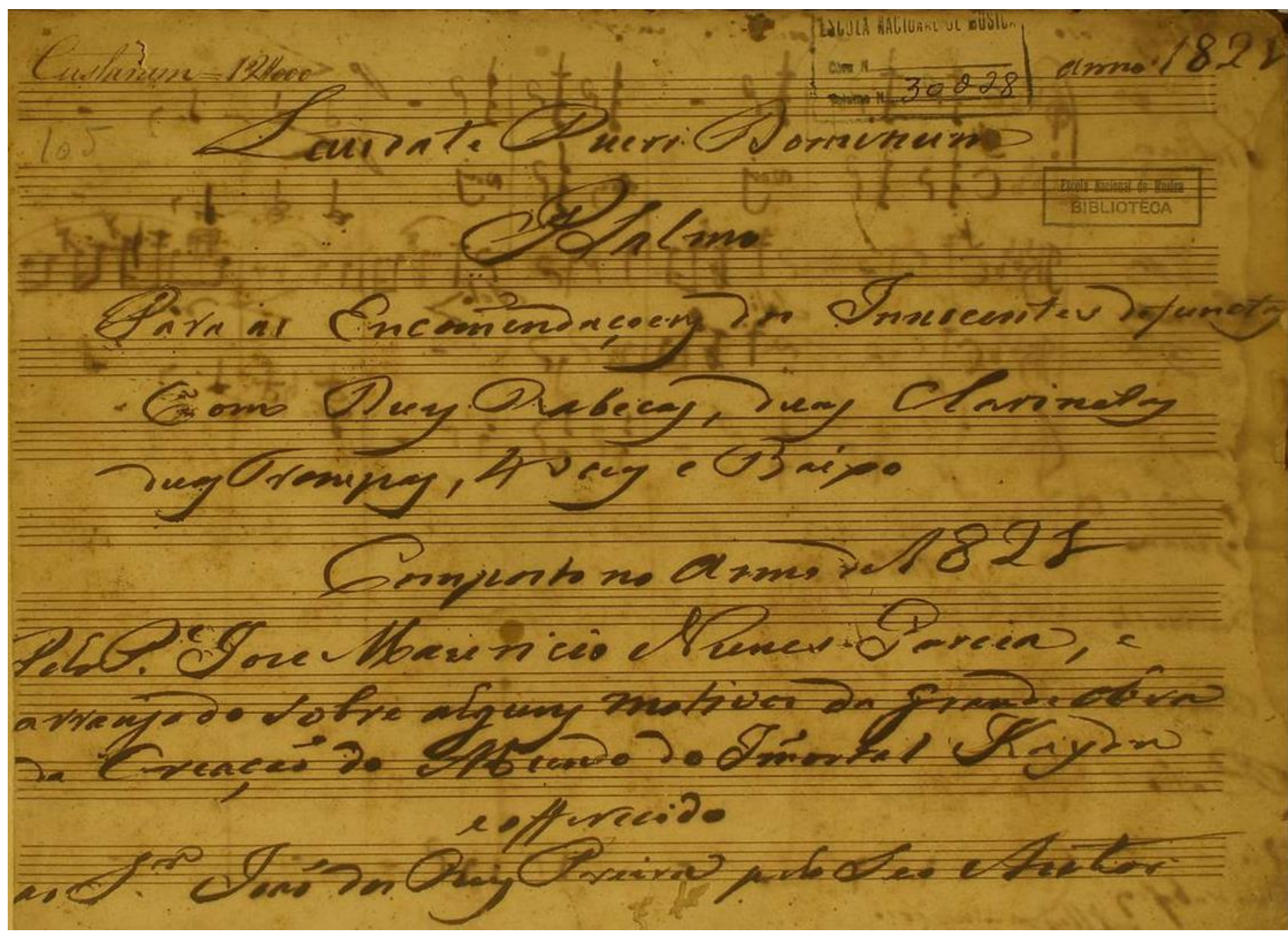

Figura 5 - Laudate Puerim Dominum (CPM79) de 1821. Carátula do manuscrito autógrafo. Fonte: BAN

Garcia usou forças semelhantes aos dois salmos de 1813, com ligeiras diferenças de efetivo orquestral: ao invés da flauta solista, agora surgiram dois clarinetes e ambas as obras estão estruturadas em 3 movimentos, sendo que o coro final, repete formulação do inicial, havendo apenas troca textual.

O Laudate Dominum Omnes Gentes (CPM78, figura 6) tem seu primeiro movimento de orquestra e coro do primeiro verso até et veritas manet, in aeternum. Este movimento está inequivocamente vazado sobre a seção coral do fim da primeira parte da obra de Joseph Haydn (1732-1809), Die Schopfung (1798), o coro Die himmel erzahlen die Ehre Gottes. 


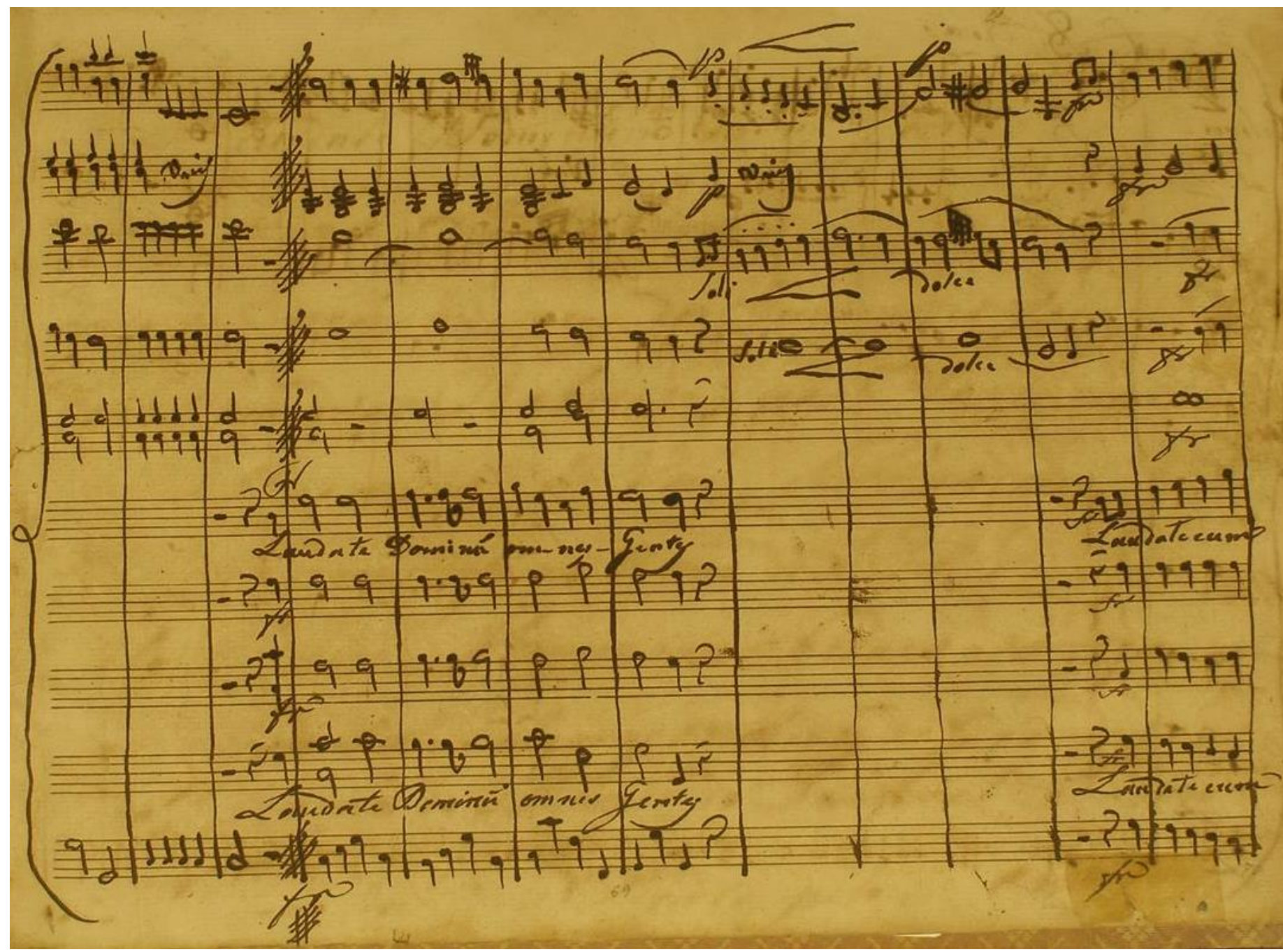

Figura 6 - Laudate Dominum Omnes Gentes (CPM78) de 1821. Entrada do coro do primeiro movimento, p. 3. Correspondência com o coro Die himmel erzahlen die Ehre Gottes, de Die Schopfung (1798), de F.J.Haydn

Foi mantida a tonalidade original de Dó Maior e a formulação de compasso da obra de Haydn (Figura 7), para o que Garcia adotou outra figuração musical por conta da troca textual e consequente encaixe prosódico. A versão de comparação nas figuras abaixo é, por motivos de adequação de espaço aqui, a primeira edição pianística de 1800.

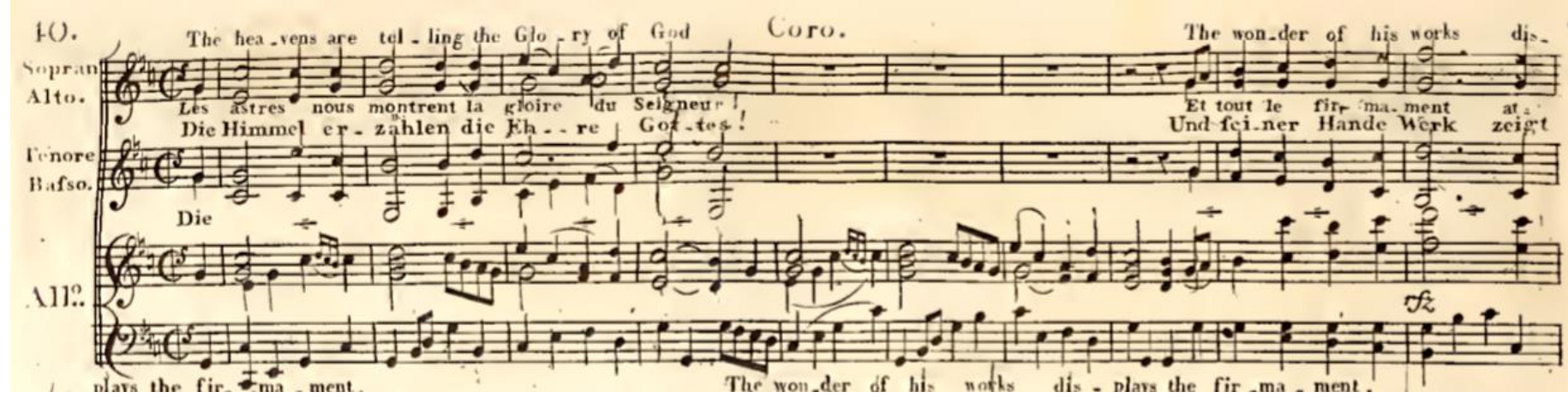

Figura 7 - Die himmel erzahlen die Ehre Gottes. Extrato de Die Schopfung, de F.J.Haydn, versão pianística de Ferdinand Ries, c. 1800 , p. 40

Desta vez Garcia introduziu elaboração orquestral um pouco mais longa da seção cantada e não incluiu tópicos musicais militares. Os tópicos da obra de Haydn de que se apropriou o brasileiro parecem ter sido mantidas até no movimento central. O segundo movimento, dividido em duas partes com arioso e ária em igual andamento de Larghetto, é um solo de contralto sobre texto do Gloria patri, que remete à herança da dramaturgia da opera seria do tempo do autor europeu. Garcia, entretanto, não se alongou ou 
desenvolveu muito tais seções. O terceiro movimento ao recuperar a formulação do primeiro com a temática do aludido coro de Haydn, recebeu o Sicut erat in principio.

O Laudate Pueri Dominum, estruturalmente idêntico ao primeiro, foi acomodado em Mi bemol Maior, também uma escolha no original trecho de Haydn que Garcia escolheu para se apropriar. Este movimento de entrada é igualmente dedicado ao coro e cobre os quatro primeiros versos, indo de Laudate pueri dominum até super caelos gloria ejus.

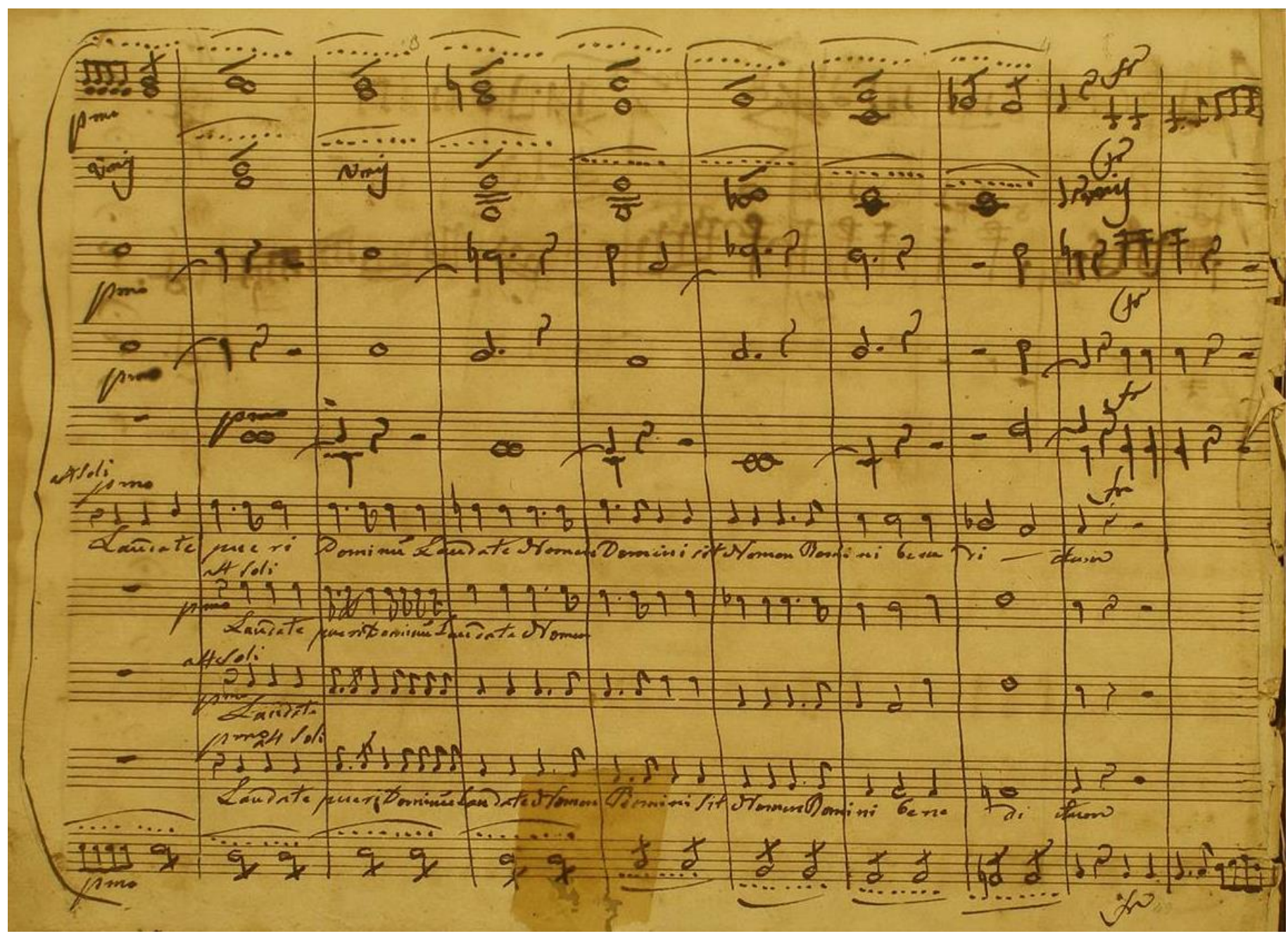

Figura 8 - Laudate Pueri Dominum (CPM79) de 1821. Entrada do coro do primeiro movimento, p. 3. Correspondência com os trechos da participação coral do Recitativo e Ária de Uriel em Die Schopfung (1798), F.J.Haydn.

Trata-se do aproveitamento de duas passagens das primeiras intervenções corais de Haydn para Die Schopfung. A primeira delas é exatamente a entrada inicial do coro após a abertura e durante o recitativo de Uriel (Figura 9). 


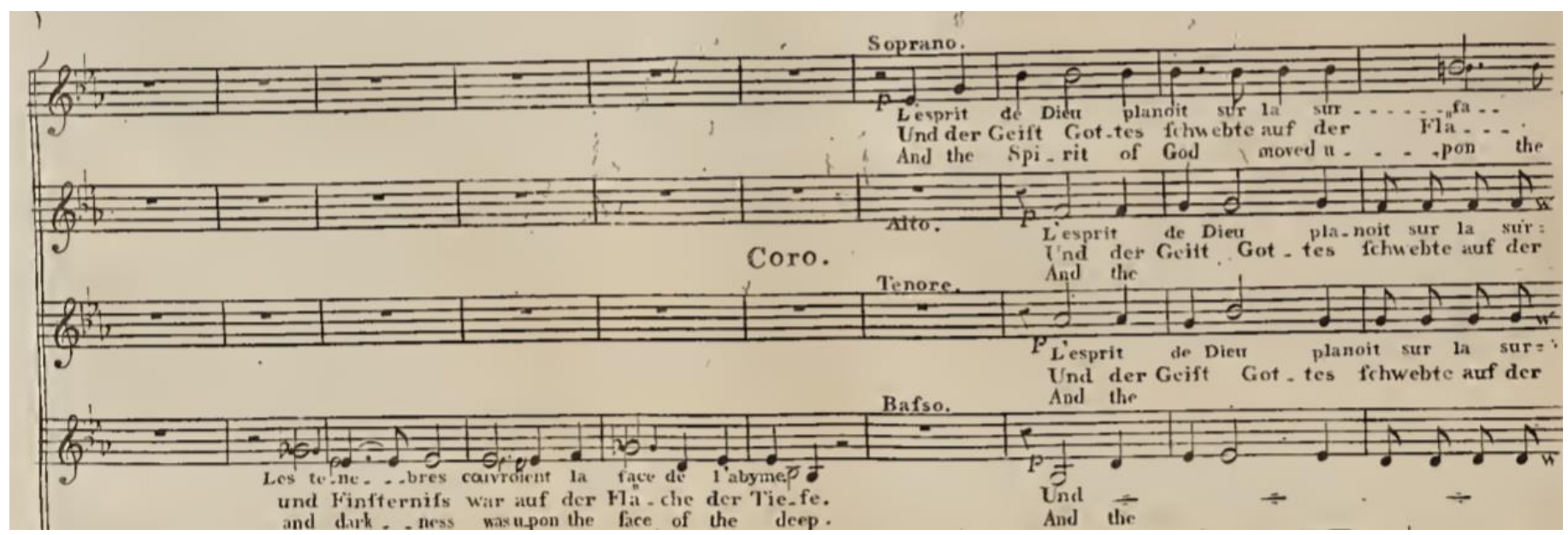

Figura 9 - Und der Geiste Gottes schwebt auf der Flache und Wasser. Extrato de Die Schopfung versão pianística de Ferdinand Ries, c. 1800, p. 4 (№1: Recitativo de Uriel e Coro)

Ainda nesta primeira seção do salmo de Garcia (Figura 12) há o aproveitamento de outro momento coral, alguns compassos adiante da primeira intervenção. Trata-se do trecho Und eine newe Welt enstpringt aus Gottes Wort (Figura 11), à qual Haydn deu mais atenção.

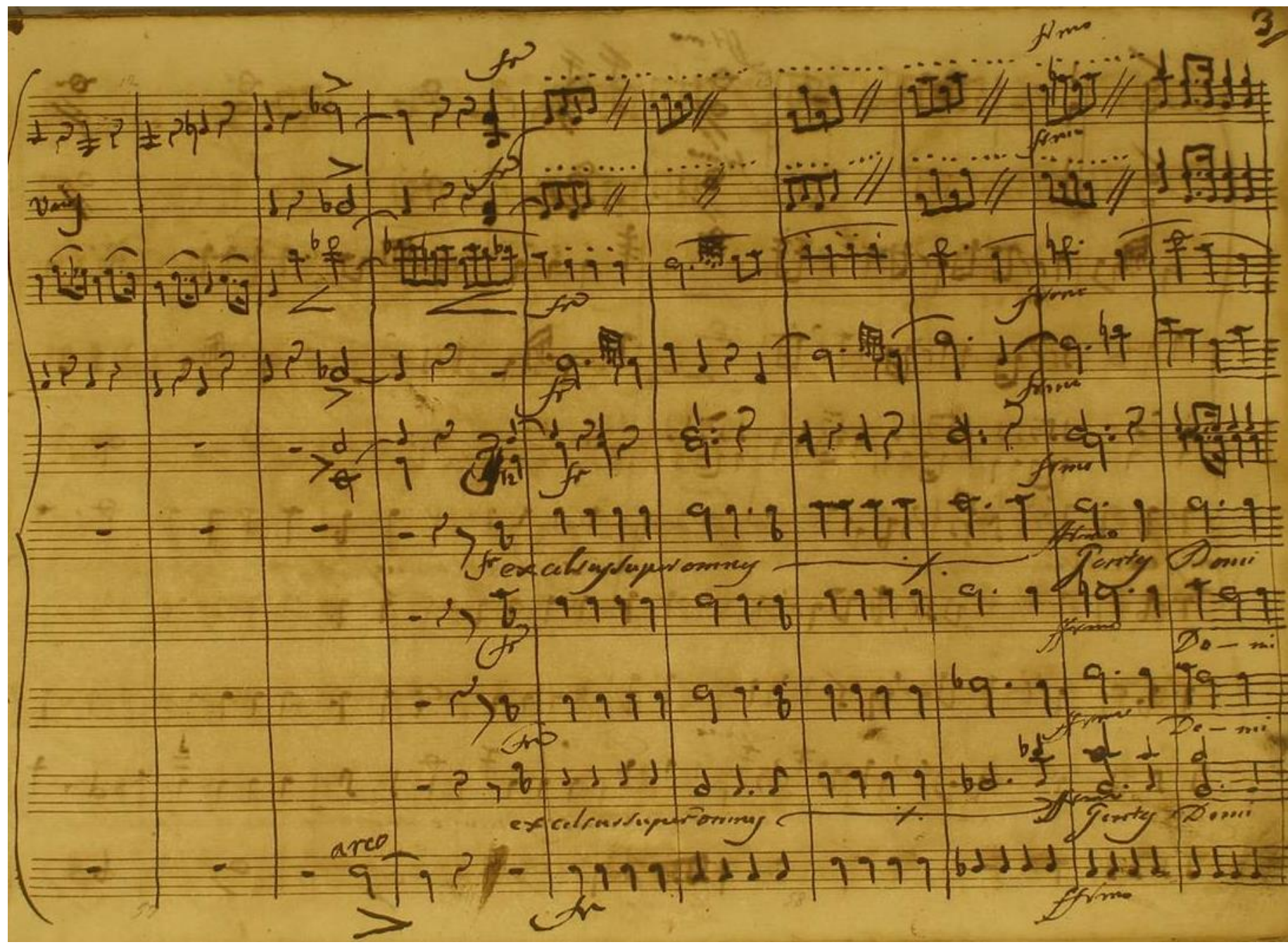

Figura 10 - Laudate Pueri Dominum (CPM79) de 1821. Primeiro movimento, p. 10. Correspondência com Und eine neue Welt entspringt aus Gottes Wort em Die Schopfung (1798), F.J.Haydn. 


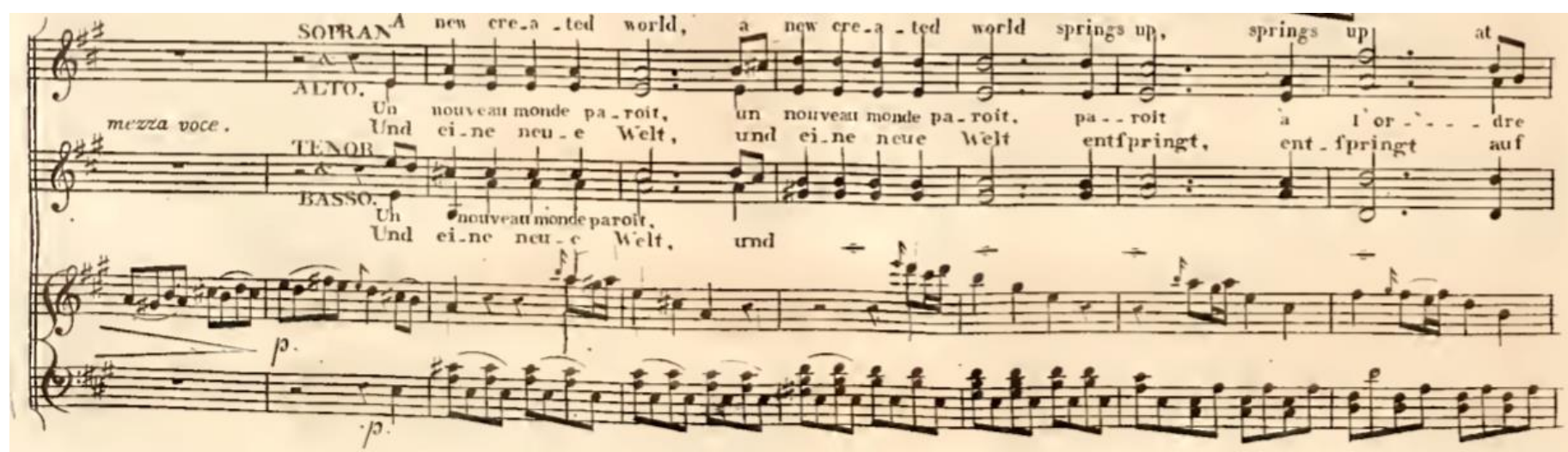

Figura 11 - Und eine neue Welt entspringt aus Gottes Wort. Extrato de Die Schopfung, versão pianística de Ferdinand Ries, c. 1800 , p. 10 (№2: Ária de Uriel e Coro)

Assim como no outro Laudate, Garcia usou a mesma elaboração para o coro final e adaptou a porção desde Suscitans in terra inopem até o fim da doxologia sobre a mesma estrutura coral, que reescreve usando variantes de figuração.

O segundo movimento é também um solo, neste caso de tenor (ou soprano, segundo indicações do autor), dividido em dois andamentos. O primeiro em Andante Moderato abrange texto desde Qui sicut Dominus Deus até Respicit in caelo et in terra. O segundo andamento é um Allegro Giusto com o mesmo texto da primeira parte.

As correlações de superposição textual podem aludir a exegesis da versão latina, que o texto usado por Haydn parece sugerir. O texto de louvor das nações do mundo a Deus e o reconhecimento da sua superioridade e proteção divinas que repousam sobre a Humanidade ficam bem completadas pela elaboração de Haydn com os versos que admitem a superioridade divina, a eternidade do firmamento, e a origem da vida, com a criação do dia e da noite:

Die himmel erzahlen die ehre gottes; / Und seiner hande Wertes zeigt ans das firmament. / Den kommendem Tag fagt es der Tag. / Die Nacht, die verschwand, der folgenden Nacht Os céus dizem a honra de Deus; / E suas mãos mostram o firmamento/ O dia fatídico é o dia. /A Noite que desapareceu na Noite seguinte

Garcia parece ter apreciado sobremaneira a elaboração de Haydn como texto Und eine neue Welt entspringt aus Gottes Wort - E um novo Mundo surgiu com a Palavra de Deus.

Estas palavras podem servir de exegese ao texto do Laudate Pueri Dominum, pois a extinção da vida terrena do inocente defunto é o momento de entrada a um mundo novo que também subsiste pela palavra de Deus. Ou seja, sequer há espaço para a tristeza, uma vez que a verdadeira alegria é habitar a eternidade ao lado d’Ele no Céu.

A corroborar esta interpretação existe um trecho de exegese na Catholic Magazine, de época próxima a estes salmos. O redator descreveu o fervor religioso de alguns momentos processionais do mundo católico, em diferentes cidades como Bordeaux e Roma e chama a atenção para um dos mais importantes, o das crianças mortas, em que se cantava o Laudate Pueri Dominum e deu notas do comportamento e dos significados de tais eventos:

But yet once more we will recall to mind one other page from the book we love to read. It is of another procession, - and of the dead. Among the olive-trees that wind their old 
roots and trunks in such fantastic shapes, - amid the orange-trees that shed their sweet perfume in the air, amid the clustering vines that wed the trees in gay and wild festoons, there is a voice of chaunting, but it is of joy not of sorrow. See it winds forward and draws near. "Laudate, pueri, Dominum, Laudate nomen Domini". Can these be the accents of death; or is it some festival of joy? Headed by the Cross, with lighted tapers in their hands, see an innocent band of children all in white, bearing a white bier and a white pall, and see that venerable priest wearing a white stole. Is it a festival of joy? And can those be tears which the mother weeps? - and for whom? Is that fair infant, beautiful as alabaster, who lies with a wreath of flowers on its head, and a cross of roses on its breast, and with that ineffably beautiful smile, which is only to be seen in sleeping infancy, - is she dead? And are those tears of sorrow which the mother weeps? She is not dead, but sleepeth. Her angel beholds the face of her Father in heaven. Those lips that have not lisped on earth, are now singing jubilee of praise in heaven. The mother weeps - but her's are tears of nature, not of sorrow; she knows that though she has lost a sweet bud on earth, she has gained a rose in heaven; and therefore, even in tears she can sing "Laudate, pueri, Dominum", for she knows that she is gone to Him "who maketh the barren in her house the joyful mother of children". "Qui facit sterilem in domo matrem filiorum laetantem". The taint of sin has been unknown; the waters of reconciliation have made this little one purer than our first parents in Eden. They, had they lived in obedience, might have deserved the continuance of their Paradise of pleasure. This little one, by virtue of the unspeakable merits of Him who gave the baptismal covenant for appliance to the souls of the faithful, has merited heaven. Truly she is not dead, but sleepeth, - her angel beholds the face of her Father in heaven! In Fest. BVM 1842 (Catholic Magazine 1842, 605-606).

\footnotetext{
${ }^{2}$ Mas, mais uma vez, vamos nos lembrar de uma outra página do livro que adoramos ler. É de outra procissão - e dos mortos. Entre as oliveiras que enrolam suas velhas raízes e troncos em formas tão fantásticas, - entre as laranjeiras que dispersam seu doce perfume no ar, em meio às aglomeradas vinhas que se casam às árvores em festões alegres e selvagens, há uma voz de cântico, mas é de alegria não de tristeza. Vê-se isso avançar e aproximar. "Laudate Pueri, Laudate nomen Domini" Pode isto ser a expressão da morte? Ou é algum tipo de festival da alegria? Com a Cruz à frente, e velas acesas em suas mãos, vê-se um inocente bando de crianças todas de branco, carregando um caixão branco e uma mortalha branca, e vê-se aquele venerável padre vestindo uma estola branca. É um festival de alegria? E o que são aquelas lágrimas que a mãe chora? E para quem? É uma criança linda, linda como alabastro, que repousa com uma coroa de flores na cabeça e uma cruz de rosas no peito, e com aquele sorriso inefavelmente belo, que só é visto na infância adormecida. Ela estará morta? E são de tristeza aquelas lágrimas que a mãe chora? Ela não está morta, mas adormecida. $O$ anjo dela contempla o rosto do Pai no Céu. Aqueles lábios que nem balbuciaram na Terra, agora estão cantando jubileu de louvor no Céu. A mão chora - mas suas lágrimas são da Natureza, não da tristeza; ela sabe que embora tenha perdido o doce rebento na Terra, ela ganhou a rosa no Céu; e mesmo entre lágrimas ela pode cantar "Laudate Pueri Dominum", porque ela sabe que ela [a criança] foi ter com Ele "que fez a estéril em sua casa, uma alegre mãe de crianças". "Qui [habitare] facit sterilem in domo matrem filiorum laetantem". A mancha do pecado é desconhecida; as águas da reconciliação tornaram este pequenino mais puro do que nossos primeiros pais no Éden. Eles, se tivessem vivido em obediência, poderiam ter merecido a continuação de seu Paraíso de prazer. Este pequenino, em virtude dos indescritíveis méritos daquele que deu o pacto batismal às almas dos fiéis, mereceu o Céu.
} 
Como nos salmos de 1813, a dedicatória destes de 1821 ainda guardam um segredo. O baixo-barítono João dos Reis Pereira (1782-1853) foi um dos mais importantes cantores do seu tempo, reconhecido pelos predicados vocais (Pacheco 2012). Curiosamente os dois Laudate a ele dedicados não possuem solo para seu registro vocal, embora possuam para os demais. Muitas hipóteses podem ser levantadas. A primeira é a de que as obras podem ter sido executadas na presença do dedicatário que por ventura perdera filhos, netos ou relativos. A segunda é de que o cantor fosse igualmente admirador de Haydn e pudesse estar encetando a direção artística ou musical de algum agrupamento em igreja ou outra instituição. Curiosamente, Pereira de quem também se sabe ainda muito pouco, talvez pela época dos salmos "não obstante achar-se já cansado, pelos seus trabalhos mais do que sua idade, há muito tempo se retirou da scena" (Diário Fluminense 1826); ainda era chamado para ocasiões em que a necessidade batia à porta, como quando do agravamento da doença do baixo Nicolau Majoranini, que deveria envergar o papel titular em Tancredi, de Rossini, naquele abril de 1826, o que só não fez com que se cancelasse a ópera porque João dos Reis Pereira assumiu a parte "com sacrifício da saúde" (Diário Fluminense 1826). Por óbvia necessidade profissional, a par de eventuais aparições como cantor podia estar desenvolvendo outra função na atividade musical para ganhar a vida.

Não é muito provável que José Maurício tenha estreado as peças, pois andava à época ainda requisitado para funções importantes, como parece do registro de datas próximas em que se confirma estar a dirigir a Real Câmara nos festejos ocorridos na Igreja de São Francisco de Paula, pelo nascimento da Princesa da Beira, com música de Marcos Portugal (Gazeta do Rio de Janeiro 1819).

O próprio José Maurício Nunes Garcia, a despeito da historiografia existente, também esteve sempre ativo até o fim, pois mesmo a um mês de seu falecimento, regeu a 19 de março de 1830 os Responsórios Fúnebres de David Perez (1711-1779), certamente o célebre Matuttino di Morti, na solenidade das exéquias de Carlota Joaquina, mãe do Imperador Pedro I (Diário Fluminense 1830), de modo a comprovar que os artistas em questão não podiam parar totalmente as atividades, por depender dos proventos que delas tiravam.

\section{Conclusão}

Os solos de ambos laudate de 1821 estão livremente baseados em trechos de diversos solos dos anjos (xibantes?) da obra de Haydn. Todas as introduções instrumentais, inclusive nas seções corais aproveitam os prelúdios e interlúdios das seções de Die Schopfung em ideias musicais e aspectos linguísticos. Garcia deixa ver aqui que trata a elaboração musical como discurso consciente e se vale de muitos aspectos, como o da tropificação, da correspondência de discursos verbal e musical e ainda o da colostrução. Este último parece evidente na compartilha de elementos musicais vários nos salmos de 1813. A colostrução, também entendida por vezes como colocação (coocorrências frequentes de elementos lexicais com elementos gramaticais) e como coligação ou fraseologismo, é no presente caso a construção de estruturas argumentativas por apropriação de um vocabulário que, quando reunidas as palavras/léxicos em torno do dito assunto, assumem um significado que tanto pode ser interno do discurso de um autor, de um grupo de falantes, ou de um processo de aprendizado ou apreensão (Gries; Wulf 2005). Não se trata apenas da frequência do uso de palavra/nota ou frases (verbais e musicais), mas do modo como são associadas e em torno de que assunto falam (Gries; Hampe; Schonefeld 2005), além de, se necessário fosse aplicar em

Verdadeiramente ela [a criança] não está morta, mas dorme, o anjo da mãe contempla a face de seu Pai no Céu. Nos festejos da Beata Virgem Maria, 1842 [Tradução do autor]. 
termos musicais, verificar os colexemas (grau de associação entre pares de eventos), o que pode vir a ser útil futuramente no caso da obra de José Maurício Nunes Garcia, dadas as suas características criativas.

Ainda assim, é fundamental que estudos de linguagem em música não percam de vista o aspecto hermenêutico ontológico, ou seja, que em busca de um sentido maior, se associem a disciplinas diversas como a História, a Sociologia e a Filosofia, dentre muitas outras a depender do analista, do objeto e da abordagem.

A origem dos dois salmos aqui considerados é o Grande Hallel, ou o tempo de festividades pascais e, sobretudo, do louvor maior, com prática que remonta aos costumes no Templo de Jerusalém. Estes são dois dos vinte salmos que contêm a palavra Alleluia (na tradução latina, Laudate) ou que a ela estiveram ligados. Mas apenas nessa associação eles ganham o sentido existencialista de que o autor brasileiro nos chama a atenção.

A sua admiração por Haydn, evidenciada por obras ou registros históricos, também precisa ser considerada quanto às fontes do próprio Haydn. Os coros escolhidos do autor europeu são alguns dos melhores exemplos em que Haydn paga tributo a Handel e a uma tradição de escrita coral dramática, que os oratórios deste último ajudaram a potencializar (Hunter; Will 2012, 103-104; 127-128). Assim, Haydn, em Die Schopfung joga com o sublime, quando parte da Representação do Caos, na Abertura, para a criação da Luz, fazendo com que todas as forças musicais, instrumentais e vocais, representem a existência (Webster 1998,67 ), assim como fazem imaginar um fim (com um novo começo) e com isso se caracteriza o projeto que Webster $(1998,67)$ chamou de estética da salvação, que parece ecoar claramente em José Maurício Nunes Garcia. Não se deve esquecer que foi pouco antes dos salmos de 1821 que se publicou no Rio de Janeiro a biografia de Haydn: "Saiu a luz A Vida de Haydn. Doutor em Múzica e vende-se na loja da Gazeta do Rio de Janeiro por $1 \$ 280 "$ (Gazeta do Rio de Janeiro 1820).

Parece enfim que a dedicatória ao "sr. Bidoloretes" ganha sua explicação. Tanto a morte era vista como escala inevitável para a alegria de chegar ao Céu e, portanto, seria necessária a valentia para superá-la, nesse caso com a louçania da juventude, inocente de pecados, assim como as obras musicais em si (os salmos de 1813) possuíam a animação, o esmero da composição e exigem elegância apurada, que seus interpretes devem refletir. A considerar o contexto de "pouca gente" e da obra "pequena" que parece marcar boa parte dos esforços do cotidiano musical brasileiro daqueles dias, as demais composições aqui se enquadram sem dificuldade no adjetivo de xibantes: são pequenas e aprimoradas expressões da devoção de um povo que vê na morte a alegria do paraíso e a ele recorre com a bravura juvenil.

\section{Referências}

Almén, Byron; Pearsall, Edward. 2006. Approaches to meaning in music. Bloomington: Indiana University Press.

Baker, Nancy Kovaleff; Christensen, Thomas. 1995. Aesthetics and the art of musical composition in the German Enlghtenment: selected writings of Johann Georg Sulzer and Heinrich Christophe Koch. Cambridge: Cambridge University Press.

Caño, Rubén Lopez. 2018. "Tristes tópicos musicales". In: Papeles Sueltos. Disponível em http://rlopezcano.blogspot.com/2018/06/tristes-topicos-musicales.html, acesso em 02-06-2018. 
Catholic Magazine 6 (69). 1842. Outubro.

Diário Fluminense. 1830. 23 de Março.

Diário Fluminense 82 (7). 1826. 13 de Abril.

Forkel, Johann Nikolaus. 1788. Allgemeine Geschichte der Musik 1. Leipizig: Scwickert.

Gazeta do Rio de Janeiro 22. 1820. 15 de Março.

Gazeta do Rio de Janeiro 40. 1819. 19 de Maio

Gries, Stefan; Wulff, Stefanie. 2005. "Do foreign language learners also have constructions? Evidence from priming, sorting, and corpora". In: Annual Review of Cognitive Linguistics (3).

Gries, Stefan; Hampe, Beate; Schönefeld, Doris. 2005. "Converging evidence: bringing together experimental and corpus data on the association of verbs and constructions". In: Cognitive Linguistics $16(4)$.

Haydn, Franz Joseph. 1800. Die Schopfung / La Création: Oratorium von J.Haydn. avec le Texte allemand, François, \& anglais. Clavierauszug v.Ferdinand Ries. Bonn: Simrock.

Hatten, Robert. 1994. Musical meaning in Beethoven: markedness, correlation and interpretation. Bloomington: Indiana University Press.

Hunter, Mary; Will, Richard. 2012. Engaging Haydn: culture, context and criticism. Cambridge: Cambridge University Press.

José Maurício Nunes Garcia. Creator alme siderum. Motetto a solo / com V.V.V. flauta a sollo, Trompas e Baxo / Pelo Pe. Me. Jozé Maurício Nunes Garcia / P a S.. Lyra S.Joanense/ Para o uzo de / Antonio Angelo da Costa e Mello. São João del-Rei: Arquivo Aluízio Viegas, da Orquestra Lira Sanjoanense.

José Maurício Nunes Garcia. 1813. Laudate Dominú Omnes Gentes. Rio de Janeiro: Biblioteca Alberto Nepomuceno.

José Maurício Nunes Garcia. Laudate Dominum Omnes Gentes Psalmo / Para as encomendaçoens dos Innocentes falecidos / com Duas Rabecas, duas Clarinetas, 2 Trompas, 4 vozes e Baixo / Composto no anno de 1821 / pelo Pe. José Maurício Nunes Garcia, e / arranjado sobre alguns motivos da grande obra / da Creação do Mundo do Imortal Haydn / e offerecido / ao Sr. João dos Reis Pereira por seu autor. Registro 398/2007. Sistema 349026 (1821). Rio de Janeiro: Biblioteca Alberto Nepomuceno.

José Maurício Nunes Garcia. 1813. Laudate Pueri [Dominum] Por José Maurício N.G. Rio de Janeiro: Biblioteca Alberto Nepomuceno.

José Maurício Nunes Garcia. Laudate Pueri Dominum Psalmo / Para as encomendaçoens dos Innocentes falecidos / com Duas Rabecas, duas Clarinetas, duas Trompas, 4 vozes e Baixo / Composto no anno de 1821 / pelo Pe. José Maurício Nunes Garcia, e / arranjado sobre alguns motivos da grande obra / da Creação do Mundo do Imortal Haydn / e offerecido / ao Sr. João dos Reis Pereira por seu autor. Registro 398/2007. Sistema 349026. Rio de Janeiro: Biblioteca Alberto Nepomuceno. 
José Maurício Nunes Garcia. 1800. Te Christe Solum Novimus / anno 1800 / Motetto a solo / com Rabecas, Flauta, viola, Trompas e Baixo / Composto em 1800 / Por José Maurício Nunes Garcia / E a elle pertence este papel. Rio de Janeiro: Biblioteca Alberto Nepomuceno.

Matos, Cleofe Person. 1997. José Maurício Nunes Garcia: biografia. Rio de Janeiro: Biblioteca Nacional.

Mirka, Danuta. 2012. The Oxford Handbook of Topics. Oxford: OUP.

Monelle, Raymond. 2006. Hunt, militar and pastoral. Bloomington: Indiana University Press.

Pacheco, Alberto. 2012. "João dos Reis Pereira". In: Dicionário biográfico Caravelas: Núcleo de Estudos da História da Música Luso-brasileira. Disponível em www.caravelas.com.pt, acesso em 02-06-2018.

Silva, Antonio de Moraes. 1789. Diccionario da lingua portugueza - recompilado dos vocabularios impressos ate agora, e nesta segunda edição novamente emendado e muito acrescentado, por Antonio de Moraes Silva. Lisboa: Typographia Lacerdina.

Sousa, Pedro Marquês de. 2012."A influencia britânica nos toques de ordenança militar portuguesa". In: Revista Militar 2524 (1). Lisboa.

Webster, James. 1998. "Haydn's vocal sacred music and aesthetic of salvation". In: Suttcliffe, Dean (Org.). Haynd studies. Cambrdige: Cambrdge University Press.

White, José Blanco (Don Leocadio Doblado). 1825. Letters from Spain. 2 ed. Londres: Henry Colburn. 